\title{
Using the IUPUI Capstone Taxonomy to Design High-Impact Practice \\ Capstone Experiences for Graduating Students
}

\author{
Tyrone McKinley Freeman, David Pierce \& Aimee Zoeller
}

\section{Introduction}

Capstones are commonplace in American higher education. Between 75\%-81\% of colleges and universities offer or require capstone courses (Hauhart \& Grahe, 2010; NewtonCalvert \&Arthur, 2018). There are, however, great variations in capstone formats and requirements, which may include research projects, internships, comprehensive exams, clinical experiences or practicums, ePortfolios, demonstrations or exhibits, performances or recitals, and client or community-based projects (Hauhart \& Grahe, 2010; Masiello \& Skipper, 2013). Kuh has identified capstones as a High-Impact Practice in undergraduate education (HIP) for enhancing student learning and development, but has repeatedly emphasized that simply offering a HIP does not, in and of itself, make it a High-Impact Practice--it must be "done well" (2008; Eynon \& Gambino, 2017, viii). So, given these variations, what constitutes a well done capstone as a high impact practice?

In an effort to address this question, faculty from across disciplines at Indiana UniversityPurdue University-Indianapolis (IUPUI) and Indiana University-Purdue University-Columbus (IUPUC) collaboratively developed the HIP Taxonomy for Capstones. This faculty resource defines research-based attributes and criteria for designing and implementing undergraduate capstones as a HIP to maximize student learning and development. This is important because capstones present unique contexts and challenges. Capstones are process-based rather than content-based, which can be a new experience for both students and instructors (Hauhart \& Grahe, 2010). Further, low student motivation and inadequate faculty time and expertise have

This is the author's manuscript of the article published in final edited form as: 
been cited as factors frustrating the capstone teaching experience for instructors (2010). Such conditions have led scholars to conclude that "designing an effective capstone course is as, or perhaps more important than simply 'teaching' one” (p. 10).

Additionally, given its location near the end of a curriculum, the capstone is, at a minimum, convenient and, at most, optimal for program assessment, especially as it relates to integrative and inquiry based learning (2010; Masiello \& Skipper, 2013). The taxonomy was created by blending these best practices to assist instructors and programs in equipping their capstone experiences for the highest impact possible for students while meeting departmental, institutional, and disciplinary goals and assessment needs. In this article, we review the process by which the taxonomy was collaboratively created and two case examples of its application on a 4-year public campus to demonstrate its adaptability across institutional, disciplinary, and curricular contexts.

\section{Development of the Taxonomy}

In 2017, IUPUI's administration created a working group to survey the landscape of capstones on campus and produce a common framework and language for it. A small subset of this group attended an American Association of Colleges \& Universities High-Impact Practices summer institute through which the university's capstone experience was defined, including five principles that must be present for a course to be considered a capstone. (See report http://hdl.handle.net/2450/11763). During the next academic year, the IUPUI Institute for Engaged Learning created a capstone community of practice charged with developing a taxonomy as a professional development tool for instructors. Faculty from twelve of seventeen schools on campus participated in the community of practice. The group met every three or four 
weeks during the academic year and engaged in a variety of ideations, facilitations, and collaborative sessions to combine their experiences with the research literature on capstones to create the taxonomy.

The taxonomy is a four-page document intended to aid instructors as they plan and teach capstone courses. It defines the capstone experience on campus and explains its rationale as being "to positively impact the career trajectory of students, preparing for the next-step that launches their career after graduation." It highlights the value of capstones for affirming teaching, learning and assessment needs and responsibilities for faculty, units, and the institution. After defining key terminology used in the document, the capstone's alignment with institutional learning outcomes is presented to contextualize capstones within both general education and disciplinary goals. The heart of the taxonomy is a $5 \mathrm{x} 4$ grid that aligns the aforementioned five principles of capstones listed as "attributes" in rows with three columns of impact labelled high, higher, and highest which describe necessary criteria for each respective level based on the literature. A capstone can have "high" impact on individual students when its effects are felt in the short-term for the duration of the course. "Higher" impact occurs when all students share experiences with each other and the effects are felt beyond the course's conclusion. "Highest" impact occurs when the capstone supports the engagement of students with their next steps after graduation and influences their resulting trajectory in a lasting way. The intent of the design is to enable instructors to start with a well-defined attribute of the capstone experience, and follow the row across the three columns to the characteristics of the desired level of impact which can affirm an instructor's existing pedagogy or inspire actions for enhancement. Two examples of such application follow below. 


\section{Case Example: Strengthening the Women, Gender, and Sexuality Studies Minor (WGSS) Capstone Experience}

While the taxonomy was created with disciplinary majors in mind, it is versatile for use with disciplinary minors, too. The WGSS Capstone is a one-credit course that typically involves a community or research project anchored in previous coursework. The primary purpose of the capstone is application of feminist theory and practices. The minor is interdisciplinary, although most courses reside in the arts and humanities and social sciences. The interdisciplinary structure presents challenges and opportunities. Application of the taxonomy allowed the WGSS coordinator to assess strengths and weaknesses of the Capstone, especially in the area of meeting disciplinary goals.

According to the highest impact for the second attribute student integration of knowledge, skills and dispositions, "Students incorporate learning from the entire undergraduate experience" and "independently and competently leverage their past experiences to achieve excellent results throughout the course." Unlike majors, there was not a clear pathway from the minor's introductory course to the capstone course. In fact, students often took an upper level WGSS elective before the introductory course. In addition, students were not required to take a theory-based course, which resulted in inconsistent understanding and application of feminist theory. A similar challenge presented itself with the third attribute, student reflection on personal and professional growth. While capstone faculty had strategically established feedback loops to "guide students to identify personal and professional purpose" ("highest" impact in the taxonomy), students may not have necessarily worked in feedback loops in prior courses and, therefore, struggled with the revision process. Guided and structured reflection was uncommon in many 100/200 level courses. In an effort to address these primary challenges, the WGSS 
coordinator worked with department chairs most closely aligned with the minor to establish purposeful pathways through 100-300 level courses that included theory, revision, and reflection.

A primary strength of the WGSS capstone was student participation in the annual intercampus student research conference, which corresponded with the fifth attribute, sharing tangible deliverables with stakeholders. The annual Indiana University WGSS Undergraduate Research Conference is attended by students and faculty from all IU campuses. It allows space for meaningful feedback for student presenters and time for informal interaction rooted in disciplinary values, such as feminist musical performances. Additionally, the conference is fully funded for both students and faculty which has facilitated its long running success. Inclusive excellence becomes possible with this model. The Capstone Taxonomy allowed the WGSS director to articulate to funders that fully financed, institutionalized dissemination channels promote interdisciplinary, feminist capstone student work at the "highest impact" because of the diverse public audiences in attendance and the multiple methods of communication presented.

\section{Case Example: Enhancing the Philanthropic Studies Capstone Experience}

In the senior capstone for the B.A. major in philanthropic studies, a new field that prepares students for careers in the nonprofit sector, students create an electronic portfolio (ePortfolio) to integrate their learning and achievement in the degree program. Instructor application of the taxonomy to the capstone revealed opportunities for enhancement in two particular areas. In relation to the second attribute of student integration of knowledge, skills and dispositions, the course initially focused on the use and reflection upon academic artifacts from previous coursework, which is listed as having "high" impact for this attribute. In an effort to move laterally toward "highest" impact, instructors expanded possible artifacts to include those 
from co-curricular experiences, such as leadership and service on campus, alternative spring break trips, study abroad, internships, community volunteering, and other engaged learning experiences in their capstone reflections. The result was greater identification and integration by students of the multiple contexts in which they had learned and practiced communication, collaboration, leadership and other important skills foundational to the degree program. Students reported increased levels of awareness of the various ways and places, both on and off campus, through which they have learned and applied core knowledge and skills from the program.

Another area identified for improvement through the taxonomy involved the fifth attribute of sharing tangible deliverables with stakeholders. Initially, capstone students presented their final projects to their peers and instructor in the classroom which is listed in the taxonomy as having "high" impact. According to the taxonomy, "higher" levels of impact could be achieved by expanding beyond the classroom itself to engage other stakeholders relevant to students. Consequently, the classroom presentations were replaced with a campus-wide public showcase of capstone projects offered in a large conference room attended by more than 50 individuals including faculty, staff, university administrators, other students, alumni as well as students' family, friends, internship supervisors, and other associates. In event and course evaluations, students reported that the public showcase was more fulfilling and meaningful than an in-class presentation as it gave them a diverse audience with which to interact.

Instructors plan to continue consulting the taxonomy per each offering of the capstone course to pursue additional enhancements. Additionally, the taxonomy helped to identify areas of professional development to enable instructors to develop the expertise necessary to effectively apply the criteria in each attribute area to increase overall impact.

\section{Conclusion}


Doing HIPs well will continue to receive focus in undergraduate education, especially as their use expands to address equity and access concerns. It is essential for instructors to be able to readily assess and reflect upon their own efforts in teaching HIPs so that all affected students have the opportunity for maximum impact in any given institutional or disciplinary context. The IUPUI HIP Taxonomy for Capstones is one tool that facilitates such reflection and enhancement for the benefit of faculty, students, and institutions. It is highly adaptable and freely accessible for use across contexts to help instructors, students, programs and institutions achieve maximum impact in their respective and collective goals.

Download the taxonomy here: https://rise.iupui.edu/resources/coursedevelopment/taxonomies/index.html

\section{Bibliography}

Eynon, B. \& Gambino, L.M. (2017). High-Impact ePortfolio Practice: A Catalyst for Student, Faculty, and Institutional Learning. Sterling, VA: Stylus Publishing, LLC.

Hauhart, R.C. \& Grahe, J.E. (2010). Designing and Teaching Undergraduate Capstone Courses. San Francisco, CA: Jossey-Bass.

Kuh, G.D. (2008). "High-Impact Educational Practices: What they are, who has access to them, and why they matter." Association of American Colleges \& Universities: Washington D.C. Retrieved from https://www.aacu.org/leap/hips.

Masiello, L. \& Skipper, T.L. (2013). Writing in the Senior Capstone: Theory \& Practice. Columbia, SC: University of South Carolina National Resource Center for the First-Year Experience and Students in Transition.

Newton-Calvert, Z. \& Arthur, D.S. (2018). Capstone Courses and Projects, In K. E. Linder \& C. M. Hayes (Eds.). High-Impact Practices in Online Education: Research and Best Practices (165-182). Sterling, VA: Stylus Publishing, LLC. 